\title{
The Mysore Declaration
}

\author{
Peter Lepping ${ }^{1}$ MD MRCPsych MSc and \\ B. N. Raveesh ${ }^{2}$ MBBS MD(Psy) MSc LLB MBA PGDMLE PGDMLS
}

'Consultant Psychiatrist and Associate Medical Directo (Betsi Cadwaladr University Health Board) and Honorary Professor (Bangor University); Centre for Mental Health and Society. Wrexham Academic Unit, Technology Park, Wrexham, Wales, UK, email peter.lepping@ wales.nhs.uk

${ }^{2}$ Professor and Head, Department of Psychiatry, Mysore Medical College and Research Institute, Mysore, India

\begin{abstract}
Coercion is recognised as a problem in health services around the world. Very little is known about the use and utility of coercive measures in psychiatry and other medical specialties in India, although the existing evidence supports the view that coercion is widely used. In February 2013 experts from India and Europe came together in Mysore, India, for an international symposium on coercion. A Declaration was drafted, discussed and ratified which defines coercive measures for the Indian context and which outlines ways to minimise coercion in medical settings in India. This paper describes the main points of the Declaration.
\end{abstract}

\section{Background}

Coercion is recognised as a problem in health services around the world. There is a growing body of evidence analysing the prevalence of coercive measures as well as randomised controlled trials comparing various types of coercion (Abderhalden et al, 2008; Steinert et al, 2010). Recent studies of 'leverage' have opened up the field to include soft pressures exerted on patients by services (Monahan et al, 2005; Burns et al, 2011). Almost the entire current literature comes from higher-income countries. Very little is known about the use and utility of coercive measures in psychiatry and other medical specialties in India. What evidence there is supports the view that coercion is widely used, although patterns of its use may differ. Some evidence suggests that there are relatively high levels of cooperation between family members and clinicians in the use of coercive measures (Srinivasan \& Thara, 2002).

There has been a rapid change in the socioeconomic, cultural and psychosocial profiles of the traditional, rurally oriented and family-centred societies of India and Asia in general. Despite the fact that family and friends are often intimately involved in patients' care in India, standards of coercion and restraint have not been defined. With a lack of international comparisons it is all the more important to be aware of patients' individual rights and preferences regarding the necessity, mode and place of psychiatric treatment, but also to recognise the legitimate interests and wishes of family members. The recent draft proposal to amend the Indian Mental Health Act has not brought certainty to issues of coercion (Shah \& Basu, 2010).

\section{Drafting of the Declaration}

In February 2013 experts from India and Europe came together in Mysore, India, for an international symposium on coercion (on which see http://www. mysorecoercion.com/content/mysore-declaration). The experts included members of the newly founded Indian Forensic Mental Health Association and the European Violence in Psychiatry Research Group. The meeting was supported by senior staff from Betsi Cadwaladr University Health Board and Bangor University (North Wales, UK). A Declaration was drafted, discussed and ratified which defines coercive measures for the Indian context and which outlines ways to minimise coercion in medical settings in India.

\section{The Declaration}

The Declaration asserts that:

There is an urgent need for the recognition and implementation of the rights of persons with mental illness, following principles with regard to equality, security, liberty, health, integrity and dignity of all people, with a mental illness or not.

It goes on:

All parties responsible for the care and treatment of mental illness should work towards the elimination of all forms of discrimination, stigmatisation and violence, cruel, inhumane or degrading treatment. We affirm that disproportionate, unsafe or prolonged coercion or violence against persons with mental illness constitutes a violation of the human rights and fundamental freedoms and impairs or nullifies their enjoyment of those rights and freedoms. We will strive to uphold the human rights of persons with mental illness. We will work towards the prevention of violation, promotion and protection of their rights.

The Declaration recognises the potential tension between the rights of patients who refuse medication and the benefits of potential restoration to normal functioning through involuntary treatment, as well as the wishes of family members, who often play an important role in the treatment of mental illness in India. The Declaration states that:

Notwithstanding this debate, persons with mental illness are entitled to the equal enjoyment and protection of al human rights and fundamental freedoms in the political, economic, social, cultural, civil or any other field.

It reiterates the rights and responsibilities of patients as well as society towards persons with mental illness. There is an emphasis on capacity and patient rights, but the Declaration also focuses on facilities and least restrictive treatment. It suggests that a balance has to be struck between patients' autonomy and the suffering that no treatment may cause. The Hawaii Declaration (see http://www.codex.vr.se/texts/hawaii.html) suggests that compulsory treatment may (or even should) 
be given provided it is done in the best interests of the patient. Patients should nonetheless be encouraged to participate as fully as possible in all decisions about their care.

The role of the family in caring for people who are mentally ill in India needs due consideration. The Declaration takes into account this specific Indian context:

The family in India plays a major role in health seeking for its constituents. Any intervention planned for the patient should take into account the family's considerable influence over many aspects of patient management, including outpatient consultation and continuing care.

The Declaration names possible barriers standing in the way of achieving the desired standards. Barriers are partly of a legal nature because the Indian Mental Health Act does not, for example, define when a patient is competent to make decisions. There is no separate provision for enforced treatment. However, there are clear rights for people with mental illness under the Indian Constitution (Pyle, 2004). Additional barriers include lack of awareness, prejudice, lack of resources and lack of adequate advocacy. The Declaration sets out measures that are needed to overcome such barriers and in so doing describes a potential road map to achieving less coercion in India:

- raising awareness

- benchmarking, using validated tools to count and document the use of coercive measures

- agreeing a definition of restraint and other coercive measures.

Standardisation and benchmarking are internationally recognised as ways to drive forward quality improvements. In addition, guidelines for the use of medication should be developed regionally or nationally. They should be based on evidence, and be practical in the Indian context. Guidelines for restraint and rapid tranquillisation can improve safety and avoid idiosyncratic practice (Lepping, 2013). Staff training both to reduce the use of coercive measures (including training in control and restraint that emphasises physical restraint as the intervention of last resort) and to introduce safer methods of restraint has proved an effective measure in many parts of Europe. Comparisons of benchmarking results have been another important tool in Europe. This allows the identification of areas where practice is outside the norm, which can then be prioritised for intervention.

The Declaration defines various types of restraint for the Indian context. An agreed definition of restraint allows better communication without misunderstandings between various stakeholders. The Declaration asserts that the phrase 'violence and/or coercion against a person with mental illness' means an act of violence that results in or is likely to result in physical, sexual, economic or psychological harm or suffering to a person with a mental illness, including threats of such acts, coercion or arbitrary deprivation of liberty, whether occurring in public or in private life. The definitions cover physical restraint, chemical restraint, mechanical restraint, environmental restraint, seclusion and psychological restraint. The Declaration broadly separates unplanned and planned restraint.

Legal and policy reform is a key strategy identified to promote human rights. Mental health policies and laws in low- and middle-income countries often fail to incorporate current international human rights and best practice standards to prevent violation of human rights (Drew et al, 2011). The Mysore Declaration should stimulate advocacy and education campaigns, and it suggests establishing legal and oversight mechanisms to prevent human rights violations.

In order to achieve these goals the Declaration calls upon healthcare providers in India to develop strategic plans. Benchmarking, regular analysis of data, regional, national and international comparisons and transparency can help to raise awareness and allow key stakeholders to prioritise funding where deficiencies are identified. Organisational strategies will be needed to implement training and raise awareness. This will require the support of senior management in stakeholder organisations. Raising awareness among patients and their families will be an important aspect of any national strategy.

The full Declaration is available online at http://www.mysorecoercion.com/content/mysoredeclaration.

\section{References}

Abderhalden, C., Needham, I., Dassen, T., et al (2008) Structured risk assessment and violence in acute psychiatric wards: randomised controlled trial. British Journal of Psychiatry, 193, 44-50.

Burns, T., Yeeles, K., Molodynski, A., et al (2011) Pressures to adhere to treatment ('leverage') in English mental healthcare. British Journal of Psychiatry, 199, 145-150.

Drew, N., Funk, M., Tang, S., et al (2011) Human rights violations of people with mental and psychosocial disabilities: an unresolved global crisis. Lancet, 378, 1664-1675.

Lepping, P. (2013) The use of emergency medicine: a survey from 21 countries. Journal of Clinical Psychopharmacology, 33, 240-242.

Monahan, J., Redlich, A. D., Swanson, J., et al (2005) Use of leverage to improve adherence to psychiatric treatment in the community. Psychiatric Services, 56, 37-44.

Pyle, M. V. (2004) Constitutional Government in India. S. Chand \& Co.

Shah, R. \& Basu, D. (2010) Coercion in psychiatric care: global and Indian perspective. Indian Journal of Psychiatry, 52, 203-206.

Srinivasan, T. N. \& Thara, R. (2002) At issue: management of medication noncompliance in schizophrenia by families in India. Schizophrenia Bulletin, 28, 531-535.

Steinert, T., Lepping, P., Bernhardsgrütter, R., et al (2010) Incidence of seclusion and restraint in psychiatric hospitals: a literature review and survey of international trends. Social Psychiatry and Psychiatric Epidemiology, 45, 889-897. 